\title{
(Re)existência e potência de vida: práticas integrativas e complementares em saúde para presos
}

\section{| ${ }^{1}$ Marisangela Spolaôr Lena, ${ }^{2}$ Tonantzin Ribeiro Gonçalves |}

Resumo: Este trabalho objetivou discutir como as Práticas Integrativas e Complementares em Saúde (PICS) têm sido uma possibilidade de saúde e existência a presos que frequentam a Associação Cultural de Desenvolvimento do Apenado e Egresso (ACUDA) de Porto Velho, RO. Foi realizada uma pesquisa etnográfica durante quatro meses envolvendo observação participante das atividades diárias promovidas pela Associação, bem como entrevistas em profundidade com presos e funcionários. A ACUDA atendia cerca de noventa presos do sistema fechado, oriundos de três casas prisionais da cidade. A rotina diária incluía, além da oferta de PICS, atividades laborais, educacionais, de lazer e espirituais. A partir de uma leitura pós-estruturalista dos dados e enfocando as trajetórias de dois presos, discute-se que as PICS se apresentavam como potencializadoras de vida. As PICS agenciavam potência de vida a partir de Práticas de Afeto, de Cuidado, de Liberdade e de Cidadania, as quais demonstraram ser uma importante ferramenta de mudança, abrindo outras possibilidades de vida e sentido aos presos. Discute-se que, para que haja uma reintegração social efetiva dos presos, práticas como estas, que almejam a transformação individual, precisam ser aliadas a mudanças de cunho social que reconheçam a cidadania e os direitos dessas pessoas.

> Palavras-chave: Terapias Complementares; Prisões; Potência de Vida.

\author{
1 Universidade do Vale do Rio dos \\ Sinos. São Leopoldo-RS, Brasil \\ (marisangelaslena@gmail.com). \\ ORCID: 0000-0002-0053-7954 \\ 2 Universidade do Vale do Rio dos \\ Sinos. São Leopoldo-RS, Brasil \\ (tonanrib@yahoo.com.br). \\ ORCID: 0000-0003-0249-3358
}

Recebido em: 25/07/2019 Aprovado em: 06/11/2019 Revisado em: 24/05/2021 


\section{Introdução}

A situação humanitária dos presos brasileiros é bastante preocupante e um grave problema social. Prisôes superlotadas, com péssimas condiçôes de higiene, alimentação e escassas ofertas de saúde, em um ambiente que reproduz violência e que não tem promovido a reintegração destas pessoas de forma que não reincidam (ADORNO, 1991; BARCELLOS, 2010, MINAYO e CONSTANTINO, 2015).

Na tentativa de melhorar as condiçóes de vida e saúde dos presos, ampliando as açôes do Sistema Único de Saúde (SUS), em 2014 o Ministério da Saúde lançou a Política Nacional de Atenção Integral à Saúde das Pessoas Privadas de Liberdade no Sistema Prisional (PNAISP). A PNAISP surgiu após dez anos de aplicação do Plano Nacional de Saúde no Sistema Penitenciário, buscando ampliar suas açóes (BRASIL, 2014). A Política está vinculada à Política Nacional de Atenção Básica (PNAB), visando garantir acesso dessa população à rede de saúde, qualificando a atenção no âmbito prisional. Porém, ainda que o SUS seja o único dispositivo de saúde disponibilizado aos presos, o acesso é ineficiente, sendo que a maior parte dos presídios não dispóe de serviço adequado (PORTO, 2008). Há dificuldades na continuidade de açôes preventivas e de assistência, baixa cobertura e poucos profissionais, que enfrentam um ambiente insalubre, propício ao adoecimento e à transmissão de doenças (PORTO, 2008; JESUS, SCARPARO e LERMEN, 2013).

Bernardes, Pelliccioli e Guareschi (2010) apontam que a vida sob situaçôes tão adversas de periculosidade e de subsistência pode ser entendida como potência, ou seja, como resistência e insistência que cria alternativas frente a desqualificação da vida. Para esses autores, a compreensão filosófica de potência de vida é indispensável no cuidado em saúde, pois se relaciona à ideia de vida como um processo de reinventar-se, de criar maneiras de agregar-se, elaborar sentidos e dispositivos de valorização. Nesse sentido, Arendt (1989) aponta que o grande potencial humano reside na capacidade de produção de obras, feitos e palavras. Com isso, mesmo sob as condições de extrema precarização, como nos presídios brasileiros, se revelariam potências.

Segundo Deleuze (2006), produzir saúde diz respeito a olhar para a afirmação da vida que se encontra nas diversas formas de existência possíveis. A potência de vida acontece no coletivo, visto que envolve as relações, a capacidade de produzir laços, de inventar desejos, formas de vida e associaçôes (BERNARDES, PELLICCIOLI e GUARESCHI, 2010). Assim, a potência de vida e a produção da saúde associam-se 
ao afeto, à potência de agir e à construção de formas de vida possíveis (MACHADO e LAVRADOR, 2009).

$\mathrm{Na}$ tentativa de produção de saúde e reintegração social a partir da potência de vida, uma instituição tem se destacado pelas atividades proporcionadas para presos, em Porto Velho, há cerca de vinte anos. A Associação Cultural e de Desenvolvimento do Apenado e Egresso (ACUDA) oferta, além de atividades laborais, culturais, sociais, espirituais e religiosas, Práticas Integrativas e Complementares em Saúde (PICS).

As PICS representam uma grade diversidade de práticas de cuidado não biomédicas instituídas como política de saúde no Brasil por influência da Organização Mundial de Saúde (OMS) (MALLMANN e ROCHA, 2017), que passou a incentivar o seu uso de práticas de cuidado milenares e de culturas locais como estratégia de saúde (OMS, 2014). Para Luz (2005), muitas destas práticas apontam para a integralidade, tanto na concepção de indivíduo como de cuidado, entendendo esse último como processo de tratar, respeitar, acolher e atender o indivíduo nas suas necessidades. Embora representem um conjunto heterogêneo, de modo geral, as PICS podem ser classificadas como Medicinas Tradicionais e Complementares, incluindo produtos, práticas e profissionais que não são parte da Medicina convencional e que não estão totalmente integradas ao sistema de saúde.

Conforme a Política Nacional de Práticas Integrativas e Complementares em Saúde (PNPIC), as PICS compreendem tanto sistemas médicos complexos, como recursos terapêuticos, que visam, em grande parte, o estímulo de mecanismos naturais de prevenção e recuperação da saúde via tecnologias eficazes e seguras, através de escuta acolhedora, desenvolvendo vínculos terapêuticos e integrando o indivíduo com o seu meio. Ainda, muitas dessas práticas valorizam uma visão ampliada do processo saúde-doença-cuidado (BRASIL, 2006). Tesser (2009) coloca que o emprego das PICS na perspectiva da integralidade pode auxiliar na transformação das trajetórias pessoais e nas relações dos indivíduos pois, além do cuidado individual, podem proporcionar valores e práticas de promoção de saúde coletivas, almejando auxílio mútuo, solidariedade e empoderamento comunitário.

Portanto, frente às escassas oportunidades de saúde nas prisóes e considerando os inúmeros problemas na assistência prisional, buscamos, a partir das trajetórias e discursos de presos que frequentam a ACUDA e que recebem e aplicam PICS, analisar de que forma o uso destas práticas promovem a potência de vida. 


\section{Metodologia}

Esta foi uma pesquisa qualitativa de cunho etnográfico. Para Geertz (1989), a etnografia produz informaçóes a partir da imersão num determinado campo de pesquisa. Caprara e Landim (2008) atentam que esta imersão deve ocorrer por tempo suficiente para conviver intimamente com os interlocutores, buscando a sistematização e elaboração compreensível de um grande número de dados sobre o fenômeno.

A inserçáo da primeira autora no campo de pesquisa iniciou com uma visita a ACUDA para pactuar como o estudo aconteceria e aproximar-se do funcionamento da Associação e dos interlocutores. Um ano depois, a pesquisadora permaneceu quatro meses frequentando a ACUDA, realizando observaçôes, ouvindo presos, familiares, funcionários e voluntários, além de participar ativamente de diversas atividades, tendo como foco as PICS. Foram contatados funcionários e coordenadores da Secretaria de Estado e Justiça de Rondônia e da Secretaria de Saúde Prisional de Porto Velho, visando confrontar situaçóes observadas na ACUDA e/ou relatadas pelos presos durante a pesquisa. Seis presos que participavam das açóes, três funcionários e a equipe diretiva da Associação também foram entrevistados em profundidade. As entrevistas foram gravadas em áudio e transcritas. As observaçôes e impressōes sobre as entrevistas foram registradas em um diário de campo, que resultou em mais ou menos sessenta páginas.

O trabalho de campo iniciou após a aprovação pelo Comitê de Ética em Pesquisa da UNISINOS (CAAE 70589317.9.0000.5344), mediante anuência da Direção Geral da ACUDA. Os participantes do estudo foram informados sobre seus objetivos e assinaram um Termo de Consentimento Livre e Esclarecido (TCLE). Os nomes escolhidos para representar os sujeitos de pesquisa são fictícios, baseados na sugestão de um deles.

A análise etnográfica dos dados se deu a partir de alguns passos: (ANGROSINO, 2009): 1) manejo dos dados através dos arquivos eletrônicos e do diário de campo; 2) leitura panorâmica do material, destacando partes importantes e reflexóes iniciais e 3) e delimitação de categorias com a análise aprofundada dos registros e do referencial teórico. A análise se desenvolveu no confronto de elementos provenientes das observaçóes e entrevistas, apontando convergências e divergências e situando seu contexto sociocultural (CAPRARA e LANDIM, 2008). Além de situar e descrever o campo da pesquisa, se construiu narrativas que ilustravam 
aspectos centrais do objeto de pesquisa, selecionando-se, para tanto, as trajetórias de dois interlocutores. Tendo essas narrativas como fio condutor, posteriormente, discutimos os achados a luz de categorias analíticas teóricas, delimitando-se como o cenário de utilização de algumas PICS se constituíam como Práticas de Afeto, Cuidado, Cidadania e Liberdade (DELEUZE, 2006; FOUCAULT, 1995; 1999; 2006; ESPINOSA, 2008).

Visando a uma maior objetividade da narrativa, optamos por utilizar a terminologia genérica "PICS", ao longo do manuscrito para referir-se às práticas utilizadas na ACUDA. Entendemos que as PICS representam uma grande heterogeneidade em termos filosóficos e de práticas, sendo que o foco de análise se constituía muito mais na forma como as PICS eram utilizadas na ACUDA do que nas suas particularidades. Ainda assim, quando necessário, as PICS especificamente referidas seráo citadas no decorrer do texto.

As vinhetas das entrevistas apresentadas no texto estão redigidas na língua portuguesa padrão, de forma a não (des)qualificar os sujeitos (GARCEZ, BULLA e LORDER, 2014).

\section{Resultados e discussão}

Segundo o Infopen (2017), o Estado de Rondônia possuía, em 2016, 10.832 indivíduos presos e Porto Velho contava com 3.783 presos. Durante a pesquisa (agosto a dezembro de 2017), a ACUDA atendeu cerca de noventa presos de três casas prisionais de Porto Velho.

A Associação tinha estrutura própria e estava situada dentro do complexo prisional. De segunda à sexta-feira, os presos iam até a Associação acompanhados por agentes penitenciários. Ao chegar, retiravam-se as algemas e os agentes faziam a escolta do lado de fora. Não havia agentes e nenhum tipo de segurança armada dentro da ACUDA, mas todos os espaços eram monitorados por câmeras, que transmitiam imagens, em tempo real, para uma sala da Direção.

A seleçáo dos presos que participavam da ACUDA era realizada pelos diretores das casas prisionais. Ao chegarem à ACUDA, alguns presos, responsáveis por apresentar a estrutura e as regras, acompanhavam o novato que, depois, lia e assinava um termo junto à pedagoga, onde constavam todas as suas obrigaçôes e direitos ao estar na Associação. 
A rotina diária dos presos iniciava às $7 \mathrm{~h} 30 \mathrm{~min}$ com meditação, oração, depois seguiam para as PICS (práticas e/ou oficinas de aprendizado) e oficinas laborais (de mecânica de motos, de carros, de tapetes, de música, de escultura e marcenaria). As atividades eram organizadas conforme as necessidades dos frequentadores e coordenada por presos monitores e encerrando-se às $17 \mathrm{~h} 30 \mathrm{~min}$, quando regressavam às prisóes. Decisóes administrativas, de funcionamento e investimento do que era arrecadado na venda dos produtos produzidos e serviços prestados pela Associação eram tomadas pelo Presidente, pelo Diretor e pelos Associados (dentre os quais presos e pessoas da comunidade que pagavam mensalidades).

Durante as observaçôes foram ofertadas onze PICS aos presos: Reiki, Yoga, Meditação, Massagem Ayurvédica, Cone Chinês, Cromoterapia, Auriculoterapia, Constelação Familiar, Banho de argila com ervas medicinais e Eneagrama. Somente a Constelação Familiar e o Eneagrama não eram ofertados por presos, pois nenhum tinha ainda recebido formaçáo para tal, sendo disponibilizadas por terapeutas voluntários e/ou contratados pela Associação. A regularidade das ofertas era definida pela equipe diretiva e terapêutica. A Meditação era uma atividade ofertada a todos, diariamente pela manhã. Já o Reiki, Yoga, Massagem Ayurvédica, Cone Chinês, Cromoterapia e Auriculoterapia eram ofertadas em dias e turnos específicos. A Constelação Familiar, o Banho de Argila e o Eneagrama aconteceram uma única vez durante a pesquisa. Além de receber as PICS, os presos podiam fazer cursos de formação para aplicá-las.

Mesmo sendo bastante criticada pela sociedade e sob risco constante de ter seus recursos cortados, a ACUDA já atendeu cerca de três mil presos, conforme o Diretor. $\mathrm{Na}$ Secretaria de Justiça e entre os funcionários da Associação parecia não haver unanimidade referente ao apoio às atividades com os presos e, no geral, percebia-se a incredulidade de alguns quanto a possibilidade de uma efetiva reintegração social.

As duas histórias que ilustram o trabalho poderiam representar muitos presos brasileiros. O perfil deles não é diferente do que apontam estudos sobre a população prisional (ARÁN e PEIXOTO JÚNIOR, 2007; MINAYO e CONSTANTINO, 2015): homens negros, com baixa escolaridade, nascidos em famílias com poucos recursos, que não tiveram a presença dos pais na criação, tendo as mães assumido seus cuidados e de seus irmãos. Por outro lado, esses dois homens talvez se diferenciem pela sua participação ativa nas açôes promovidas pela ACUDA. 
A primeira trajetória a ser apresentada é a de Netuno (Quadro 1), um dos presos mais antigos na ACUDA (seis anos). Era um dos principais terapeutas, fez todas as formaçóes ofertadas e era sempre muito prestativo e envolvido nas atividades.

\section{Quadro 1. Trajetória de Netuno}

Netuno nasceu em Porto Velho, mas foi criado no interior do Estado, pela mãe. Ao completar um
ano, seu pai os deixou. Teve treze irmãos ao total, sendo que sete já haviam falecido quando ele nasceu.
Contou que a mãe trabalhava muito (no campo e na pesca) para sustentá-los. Um dos irmãos foi levado
para Porto Velho e "acabou sendo criado no mundo do crime" (sic) e, quando ia visitá-los no interior,
batia na mãe, nos irmãos e nele: "Então eu fui crescendo com uma mente meio criminosa, eu nunca roubei,
nunca vendi droga, nunca assaltei ninguém, nunca consegui um caroço de sal com dinheiro errado, mas eu
tinha a mente criminosa. Tudo para mim eu tinha que matar; era matar, matar, matar".

Aos doze anos, Netuno decidiu matar esse irmão, mas quando ia disparar, a mãe apareceu na frente e ele acabou desistindo em respeito a ela. Depois, nunca mais apanhou do irmão que passou a respeitálo, levando-o a concluir que: "Então tem que ser um cara ruim para ter respeito por ai também". Por isso, agradecia a Deus por estar preso, pois poderia ter matado muitas pessoas. Sobre isso descreveu que planejava matar a família da pessoa que o denunciou para a polícia, mas foi preso antes de efetivar o plano. Conhecer a ACUDA, segundo ele, foi a melhor coisa que aconteceu na sua vida, pois mudou sua forma "criminosa" de pensar: "Eu vim preso e hoje tive o prazer de conhecer a ACUDA, de conhecer a verdade, o lado da verdade, o lado espiritual, e me desviar desse caminho, dessa mente criminosa e, de certa forma, eu era um dos piores, no meu modo de raciocinar".

Além das violências vividas dentro do sistema prisional, a pior experiência de vida relatada por Netuno foi a morte da sua mãe. Sentia-se culpado por ter sido preso e tê-la abandonado, visto que nenhum dos outros irmãos cuidou dela quando adoeceu. Ele praticamente não recebia visitas e tinha pouco contato com familiares. Não tinha filhos e não relatou nenhum relacionamento afetivo. Praticamente todas as suas relaçóes eram com egressos da ACUDA e com os atuais colegas, terapeutas e pessoas vinculadas à Associação.

A segunda trajetória é a de Marte (Quadro 2), tido pela Direção como um dos exemplos do trabalho da ACUDA. Frequentava a Associação há três anos. Ele sugeriu o nome a ser usado para identificá-lo, pois era o Deus da guerra e da impulsividade. Era quem recepcionava as pessoas, tanto colegas novos, quanto pessoas que iam conhecer ou trabalhar na Associação. Recebeu todas as terapias e fez todas as formaçóes. Desde que chegou, atuou na oficina de tapeçaria e na cozinha, se estabelecendo nas terapias. Antes de ser preso, seu último emprego foi como segurança em um condomínio. 


\section{Quadro 2. Trajetória de Marte}

Marte começou cedo sua vida no mundo do crime: "Quando entrei no mundo do crime, entrei por dois motivos: primeiro porque um homem tentou pegar a minha mäe à força. Eu tinha doze anos, meu pai tinha acabado de falecer. E numa terapia recente, eu percebi que eu entrei por causa disso também. Na verdade, são três: meu pai era alcoólatra, ele teve cirrose hepática e eu nunca aceitei isso. Minha mãe não aceita, até hoje, que ele era alcoólatra. Só que ele nunca deixou faltar nada para nós. Eu era um menino quando ele foi internado, eles não tiveram o cuidado de tirar eu e meus irmãozinhos de perto. Eles não lembram porque eram muito pequenos, mas eu lembro que para levar meu pai internado colocaram camisa de força e não tiveram o cuidado de me tirar do local, de me levar para outro lugar. E ele reagindo, ele não queria ir, ele chegou a cair no chão. E eu chamava pelo meu pai e essa foi a última vez que eu vi ele vivo [...] A outra [razão] foi porque eu vi meu irmáo com uma sandália havaiana de uma cor sim e uma cor não. Não estou justificando, têm pessoas que tem mais força e vencem na vida e têm pessoas que precisam de mais cuidado. [...] Me vi na obrigação de cuidar dos meus irmáos. Eu tive que ser o cara que roubava, o cara que matava, o cara que tinha poder, para cuidar dos meus irmáos. Eu tive que ser o Cristo da história! Não me arrependo! Tenho consciência dos meus erros, mas eu não tinha maturidade".

Marte foi preso pelo estupro e homicídio de uma jovem, crimes que ele afirmava não ter cometido. O caso teve grande repercussão na mídia local e nacional, quando foi apresentada uma reportagem sobre as atividades da ACUDA na qual ele aparecia recebendo terapias. Relatou ter entrado na prisão "por baixo"(sic), pelo crime que foi acusado, e que só acabou indo parar na ACUDA (e permanecendo lá) por esse mesmo motivo. Isso porque, segundo Marte e outros presos, o crime sexual é o pior crime que se pode cometer na "lei da cadeia", sendo que muitos sofrem abusos e são estuprados, sendo excluídos da convivência dos demais: "Eu era um bandido de ponta, e eu caí com um artigo de crime sexual com homicídio. Por baixo porque é isso. Eu não odeio, eu detesto estuprador, mas me colocaram no meio, então, eu não me encaixo, eu não aceito isso, mas eu entendo. Eu vejo que eu estou sofrendo na pele o que as mesmas pessoas aqui sofrem. Então, entrar por baixo para mim é isso. Só que eu tenho uma caminhada no mundo do crime. [...] Passei uma humilhaçâo que eu não esperava passar".

Marte permaneceu na ACUDA, também, porque, logo nas primeiras terapias recebidas, começou a dar-se conta que tinha sido preso por um crime que não cometera, mas que foi por este mesmo motivo (tentativa de estupro da mãe que não foi confirmada), que ele matou pela primeira vez. Isso, como ele dizia, "o pegou". Ele sonhava constantemente com suas vítimas, chegando a vê-las na sua cela. Não sentia medo, mas isso o incomodava porque fazia rever o que tinha acontecido. Sentia arrependimento e pedia perdão a elas por todo mal que lhes causara. Revelou que isso começou a acontecer depois de ter ido para a ACUDA e que sonhava, normalmente, quando recebia Reiki.

Marte contou ter casado pela primeira vez aos 16 anos, quando foi pai. Separou-se e casou novamente (com a atual esposa), tendo mais um filho. Recebia visitas regularmente da família tanto na ACUDA quanto na prisão.

Tanto Netuno quanto Marte mencionaram que as PICS e a participação na ACUDA foram indispensáveis para mudarem aspectos de sua vida e ter alternativas que não o retorno à criminalidade ao saírem da prisão. Marte foi para a ACUDA com a intenção de fugir, pois achava que seria mais fácil não tendo tanta vigilância. 
Porém, acabou sendo "fisgado" pelas terapias. Em um dos primeiros dias, participou de uma dinâmica com um terapeuta italiano, parceiro da Associação, que trabalhava com o Eneagrama e teve uma das experiências mais intensas da sua vida, tanto pelo conteúdo suscitado, quanto por ter se sentido acolhido e respeitado. Após esse dia, decidiu não mais fugir e que iria dedicar-se a receber as terapias e a estudar para aplicá-las. Netuno, por não ter muitos laços fora da prisão, acabou adotando a ACUDA como família. Era uma das pessoas mais procuradas para aplicar as terapias (principalmente a massagem) pela sua prática e por ser reconhecido como uma pessoa muito tranquila e afetuosa.

Marte e Netuno tiveram infâncias bastante difíceis, assumindo posturas que os levaram para a criminalidade, ambos na tentativa de melhorar a vida de suas famílias e de protegê-las de alguma forma. Ao serem presos, seguiram em situaçóes de violência e precariedade, mas ao conhecer a ACUDA - um lugar que seria para fuga - encontraram possibilidades de (re)inventar formas de existência e de liberdade. Observamos que, ao receber e aplicar as terapias, os presos encaravam com seriedade o processo, havendo muito cuidado no que faziam tanto consigo, quanto com os outros. Havia cuidado no preparo para que as práticas acontecessem e bastante estudo por parte dos presos-terapeutas. Marte, Saturno e muitos outros presos, quando questionados sobre sua profissão, afirmavam ser terapeutas e que seguiriam atuando ao saírem da prisão.

Desse modo, pensamos que as PICS eram utilizadas na ACUDA enquanto potencializadoras de vida, apresentando características peculiares por serem utilizadas com um público privado de liberdade. Segundo Machado e Lavrador (2009), a potência de vida emerge como processo de criação de si na relação com o outro. Assim, apresentaremos as PICS, neste artigo, como Práticas de Afeto, Práticas de Cuidado, Práticas de Cidadania e Práticas de Liberdade, utilizando autores como Foucault (1995; 1999; 2006), Espinosa (2008) e Deleuze (2006) para discuti-las.

Ao entender as PICS como Práticas de Afeto, partimos do pressuposto de que o afeto seja o exercício de afetar e ser afetado, uma experiência subjetiva na qual o outro não é submissível a si mesmo, mas entendida como vivência de alteridade (ORTEGA, 1999). Mais do que o uso de técnicas aplicadas sobre os corpos, é a relação que é estabelecida que vai sustentar e promover o cuidado (BERNARDES, PELLICCIOLI e GUARESCHI, 2010), como foi experienciado nas relaçôes estabelecidas na ACUDA. Por exemplo, a condição para a aplicação efetiva das PICS 
envolvia o reconhecimento pelo toque, os abraços, a forma como o material era preparado, como os presos falavam sobre as terapias e a importância que davam a elas. Nestas circunstâncias, ao vivenciar as PICS na Associação, também fui afetada e estabeleci relações de afeto com muitos presos, funcionários e voluntários. A importância do afeto foi salientada por Marte: "Eu preciso de toque. (...) Pensei no colo da mãe, que pode ser a massagem, pode ser uma conversa sincera, porque nunca ninguém aqui me prometeu nada. Sempre foram na verdade. Eu nunca conheci o não, eu conheci aqui”.

Assim, as PICS pareciam ativar um determinado modo de se colocar no mundo que envolvia a corporalidade, o estar disponível ao outro, o acolhimento. Porém, se ultrapassa a dicotomia corpo-mente, propondo-se uma maneira de pensar alicerçada no corpo, mas considerando a consciência enquanto superação moral, predefinida por valores éticos de uma determinada sociedade que são marcados também pelos afetos (ESPINOSA, 2008).

Muitos presos tinham dificuldades com o toque e era comum, nos primeiros dias, não cumprimentarem ou só o fazerem à distância. Alguns diziam que não lembravam quando tinham sido abraçados pela última vez e que isso, na cadeia, era visto como uma prática homossexual como Marte relata: "O abraço?! Eu não gosto de abraço, mas eu aprendi a abraçar. [...] O abraço tem que ser verdadeiro. É coração com coração. Então, na cela eu ouvia que isso era coisa de veado”. Muitos estranhavam ao serem recebidos com abraços pelos funcionários e terapeutas, mas acabavam permitindo-se abraçar e tocar, o que se tornava comum e excepcional ao mesmo tempo, pois "quebrava" um pouco a dureza da vida na prisão e os preconceitos envolvendo o toque e o afeto.

Sobre isso, Deleuze discute o afeto, baseado em Espinosa, considerando este o resultado da ação de um corpo no outro. A afecção, portanto, refere-se ao encontro de corpos, à mistura que acontece (DELEUZE, 2006). Nesta perspectiva, a possibilidade potencializadora de auxiliar o outro a reinventar-se acontece através da valorização dos indivíduos, considerando a dimensão afetiva. Assim, Marte mencionou a mudança de perspectiva e na forma de relacionar-se com o outro:

\footnotetext{
"A gente tem o hábito de desconfiança, eu sempre tive. É olhar com outros olhos, mas é porque... Nunca ninguém tratou bem a minha pessoa como eles me tratam aqui e como qualquer pessoa que vem trabalhar aqui, ou terapeuta, ou estudante. É diferente do que eu convivia, é um tratamento diferente, é um papo diferente, olhava com outros olhos. Porque não éramos tratados bem e começamos a ser."
} 
Em especial, Marte e eu vivenciamos uma situação peculiar que nos afetou bastante. Sonhamos, na mesma noite, um com o outro. Era um sonho muito particular onde estávamos num círculo, sentados ao redor de uma fogueira e ele estava vendado. Se levantava e não conseguia caminhar porque não enxergava. Nisso, eu me levantava, pegava-o pela mão e ia auxiliando-o, até que o ajudei a tirar a venda. Para minha surpresa, ele me procurou para contar o sonho que era praticamente o mesmo. Contei para ele que também tinha sonhado e ele se emocionou muito. Ele entendia que precisava de ajuda e que tinha ficado claro, depois do sonho, que precisava de alguém para ajudá-lo a caminhar até conseguir enxergar o seu verdadeiro caminho. Senti que estávamos vinculados por um afeto capaz de promover cuidado e (re)invenção, tanto para ele quanto para mim. Neste sentido, no encontro das subjetividades estaria presente uma luta de potências que pode ser assertiva ou não (ESPINOSA, 2008). Quando assertiva, os indivíduos na ACUDA eram afetados por afetos-sentimentos-alegres, que, como resultado, aumentam a potência de agir ou a força de existir. Já quando não assertivo, prevaleciam afetos-sentimentos-tristes, levando à diminuição da potência das açôes dos indivíduos (DELEUZE, 2002).

Mesmo não sendo um serviço de saúde, o envolvimento com a ACUDA produzia um cuidado que impactava a saúde dos presos, sendo que a efetividade deste trabalho se relacionava com a qualidade do atendimento prestado, que situava o indivíduo histórica e integralmente. Desta forma, considerar o outro como sujeito na construção deste campo de cuidado, corresponde ao trabalho afetivo, visto que não busca apenas a aplicação de uma técnica (PINHEIRO e GUIZARDI, 2006).

As PICS promoviam a prática vinculada aos afetos, proporcionando novas formas de sentir, de afetar e ser afetado. Isso foi visualizado também a partir de relatos sobre o que alguns deles sentiam e das reaçóes nas sessóes de Constelaçáo Familiar. Esta era vista por muitos deles como "uma das terapias que mais mexia com suas emoçôes" (sic). Alguns presos relataram que foi na vivência desta terapia que conseguiram permitir-se sentir raiva, tristeza, arrependimento, culpa, dentre outros sentimentos e, a partir disso, sentir empatia por suas vítimas e/ou familiares. Muitos relatavam que, a partir da Constelação Familiar conseguiram perdoar seus pais, familiares ou outras pessoas que haviam lhes feito mal, incluindo a eles mesmos. A potência de vida parecia emergir deste estado de afecção.

Em alguns momentos, percebi também certa dificuldade na articulação com o outro. Em poucas circunstâncias havia articulação reflexiva após receber as 
terapias e muitos se sentiam angustiados, visto que conteúdos dolorosos e subjetivos eram mobilizados, mas não trabalhados diretamente. $\mathrm{O}$ trabalho terapêutico não parecia se encerrar na experimentação de cada prática, visto que eles relatavam ficar "ruminando" por dias o que havia sido acionado, sendo importante uma interlocução para efetivamente integrar a experiência. Sobre isso, é possível pensar que a orientação filosófico-espiritual da ACUDA, não sendo unívoca e admitindo uma diversidade de crenças e orientaçôes religiosas, não fornecia um enquadre ritualístico completo que funcionasse para concatenar essas vivências em um sistema de significados específico, ficando a cargo de cada um que fizesse isso conforme suas crenças.

As PICS também promoviam Práticas de Cuidado. Mesmo o Brasil tendo instituído a PNAISP, em 2014, esta não assegurou melhores condiçôes de saúde aos presos. Em muitas circunstâncias, a única alternativa de cuidado à saúde era por meio das PICS. Aqui, entendemos a noção de cuidado para além de uma técnica ou procedimento, mas como uma ação integral que busca entender a saúde como um direito de existir. Para Luz (2004), o cuidado é um ato de tratamento, respeito, acolhimento do sofrimento do outro, na maior parte das vezes, proveniente da sua fragilidade e condição social. A carência de atendimentos básicos em saúde nas prisôes de Porto Velho foi relatada pelos presos e corroborada por conversas informais com a Coordenadora de Saúde Prisional. Netuno comentou:

“Eles podem dizer assim: 'Não, lá tem médico, tem psicólogo, tem isso, tem aquilo outro'. Mas não tem! Você procura, você pede, você não tem. Se você faz barulho para ter, corre o risco de um colega teu falecer, perder a sua vida".

Além do descaso com a saúde, situaçôes de violência eram frequentemente vividas pelos presos, como um deles que sofria com fortes dores no ouvido e que não solicitava atendimento na prisão por medo de represálias. Segundo ele, alguns apanhavam e iam para solitárias ao pedir atendimento. A solução encontrada por ele foram as aplicaçóes de Cone Chinês na ACUDA, sendo que suas dores praticamente desapareceram.

Alguns presos com formação em PICS mencionaram aplicar terapias nos presos com os quais dividiam a cela e que não frequentavam a ACUDA. Relataram, por exemplo, fazer massagem e aplicar Reiki para aliviar tensóes na coluna por ficarem por longos períodos fechados nos pequenos espaços disponíveis. Em uma situação, Marte relata que tinha acabado de conseguir fazer massagem pela primeira vez em outro participante. Contou que este tinha sofrido abuso sexual dentro da prisão e 
não conseguia permitir que o tocassem. Marte buscou respeitar o limite dele e nas primeiras três vezes fez apenas massagem no rosto e pés. Salientou a importância daquele momento e do quanto se sentia feliz em saber que o colega conseguiu entregar-se ao processo terapêutico. O corpo é, desta forma, o meio pelo qual as experiências acontecem, nos sentimos vivos e nos relacionamos, sendo através dele que a vida mostra a sua potência (SAFATLE, 2018).

As PICS também eram vistas pelos presos como um modo de tratar tanto suas dores físicas quanto emocionais. A diminuição da necessidade de remédios era considerada um benefício das PICS, como aponta Netuno:

\footnotetext{
"Hoje eu vou muito para o lado da meditação. Eu paro, se é algo que eu vejo que estou entrando em desespero, que é uma dor ou alguma coisa, medito, faço um Reiki. Se for dor, eu coloco a mão em posição, em cima. Faço um trabalho do Reiki e faço a meditação. E quase não tomo remédio”.
}

Cabe destacar que muitos presos denunciaram a falta de assistência farmacológica nas prisóes, o que aumentava a importância das PICS.

Para Pinheiro, Machado e Guizardi (2011), as PICS podem favorecer o equilíbrio entre corpo, mente e espírito, estimulando o protagonismo no autocuidado, como atesta o relato de Netuno. As PICS possibilitariam a construção de novos significados para a saúde, rompendo e confrontando práticas de cuidado convencionais e que nem sempre estão a favor da saúde dos indivíduos (PINHEIRO, MACHADO e GUIZARDI, 2011). Embora as PICS não sejam práticas substitutivas da biomedicina, se apresentavam para os presos, na maior parte das vezes, como a única forma de cuidado disponível.

Como já foi dito, além do cuidado direto aos presos, a ACUDA ofertava PICS às pessoas da comunidade e a agentes penitenciários, sendo que as mais procuradas eram a Auriculoterapia e o Reiki. Dois agentes testemunharam que as terapias ajudavam no alívio de dores na coluna e cabeça. Assim, além do benefício direto, a aplicaçáo das terapias pelos presos nos agentes e em outras pessoas acabava por ampliar relaçóes e auxiliar na quebra de preconceitos.

As PICS utilizadas na ACUDA também promoviam o cuidado de si que, no sentido foucaultiano, está vinculado a um princípio de movimento e inquietação consigo no curso de sua existência. Trata-se, em outras palavras, de "uma atitude geral, um certo modo de encarar as coisas, de estar no mundo, de praticar açóes, de ter relaçôes com o outro" (FOUCAULT, 2006, p. 14), dando forma a atitudes para 
consigo, com os outros e com o mundo. Marte descreve como as terapias estavam provocando nele esse estado, aberto, de reflexão e construção sobre si mesmo:

"Estou num processo de crescimento! Eu estou perdido! Estou num processo de evoluçáo.
Eles me deram todas as ferramentas, só que eu preciso de cuidados. Eu não sou certo, mas
também não sou errado. Eu estou em cima do muro agora. Primeiro eu sabia que eu era
só errado, eu passei por muita terapia, por muitas pessoas que me acolheram, estudantes,
terapeutas que vinham e que me ensinaram um ofício, além de cuidarem de mim e me
fazerem enxergar que havia outras possibilidades do Marte existir. Mas eu ainda estou
descobrindo, por isso preciso de ajuda".

Como Marte indica, esse processo de criação e transfiguração é situado no mundo e na relação com os outros (FOUCAULT, 2006). Mizoguchi (2016) explicita que, para Foucault, ao enunciar uma ética do cuidado de si, há uma articulação política, já que o indivíduo não se desvincula do lugar onde vive. Era a partir deste processo de cuidado de si e de (re)conhecimento que Marte podia analisar suas relaçóes com os outros, possibilitando outras formas de expressão no mundo, criando novas realidades possíveis, que ele construía ativamente. Assim, a potência de vida, suscitada pelas práticas de cuidado de si, emergia enquanto oportunidade de mudanças e reflexão.

As PICS se apresentaram também como Práticas de Liberdade, ainda que restritas aos muros da ACUDA, pois eram importantes para o desenvolvimento dos presos enquanto indivíduos, proporcionando novas formas de ser. Foucault (2006) aponta que a liberdade não é garantida e assegurada pelas leis, mas tem a ver com a prática e com o exercício da mesma, sendo uma experiência. Os interlocutores estavam ali sob pena de privação de liberdade, mas a liberdade tratada aqui tem a ver com a efetividade política e social, estando vinculada à vida ética de constituição de si e do mundo (FOUCAULT, 2006).

As PICS praticadas na ACUDA eram, portanto, uma possibilidade de exercício de liberdade, como ilustra Marte:

"Consegui segurar mais a minha agressividade. Teve uma terapia aqui que eu achava chata e que eu acabei me identificando muito que foi a Constelaçáo Familiar. Eu comecei a ver que se eu alimentasse muito o lobo mau, eu ia ser mau e se eu alimentasse mais o lobo bom eu ia ser bom. Então, eu tinha que ter equilíbrio e o meu equilíbrio tinha outro foco, pois eu alimentava muito o meu mau. Eu tinha muita ilusão de poder, eu gostava muito de poder, de saber que eu era o cara, dinheiro, e essa ilusão tirou muito tempo da minha vida e me trouxe muitas coisas boas como ruins também". 
Neste relato percebemos como, a partir da Constelação Familiar, Marte passa a questionar-se quanto a ser quem ele era, como se relacionava com as pessoas, possibilitando pensar em outros modos de ser ele mesmo. Com isso, se travava uma "negociação" e um equilíbrio entre quem ele era e quem ele poderia ser.

Para Castro (2009), a liberdade, é uma condição essencial no exercício do poder, possibilitando a criação de resistências contra a dominação étnica, social ou religiosa (CASTRO, 2009). Assim, Marte teria liberdade para exercer a sua subjetividade, mas em um processo crítico de negociação com a realidade. Foucault (1995) aponta sua preocupação com a liberdade de invenção da ação do homem, a qual seria uma condição para o exercício do poder. A invenção de novas subjetividades possibilita resistências ativas no mundo, criando possibilidades de exercício político e ético da liberdade. Segundo Negri (2001, p. 31), "ao lado do poder há sempre a potência”. Marte não deixou de exercer o poder, mas passou a exercê-lo de outras formas, que eram socialmente aceitáveis como, por exemplo, ser um dos presos que monitorava as terapias e ajudava na organização e aplicação das mesmas.

Para Ortega (1999), Foucault buscou analisar as formas como os indivíduos se constituem enquanto sujeitos morais, considerando as relações que eles estabelecem consigo e com os outros. Nessa direção, Foucault (2006) discute o que denominou de "artes da existência", que são práticas racionais e voluntárias através das quais os indivíduos determinam regras de conduta (práticas de liberdade) buscam transformarse e modificar sua singularidade, de modo similar a confecção de uma obra de arte.

As PICS demonstraram auxiliar neste processo de (re)construção da vida dos presos. Com a entrega ao processo terapêutico, eles podiam refletir sobre as suas escolhas. Ao respeitar as normas e ao não fugir (pois muitos relataram ser este o objetivo quando pediram para ir para a Associação), recebiam mais liberdade nos processos decisórios, podiam participar de mais açóes (como a participação no projeto com os adolescentes, quando saíam da ACUDA e iam até o local onde os adolescentes encontravam-se presos), ganhando mais confiança e incentivo da equipe diretiva. Assim, novas descobertas de si podem engendrar novas possibilidades de liberdade e de participação que nos levam a entender as PICS também como Práticas de Cidadania.

Para Assis e Friede (2014), um tratamento humano e digno deve ofertar aos presos oportunidades de mudança e desenvolvimento. A maior parte dos presos, de acordo com os autores, já se encontrava à margem da sociedade antes da prisão, 
tendo origem na pobreza extrema, muitos desempregados e com pouca escolaridade. Alguns, inclusive, viviam nas ruas, sem vínculos familiares ou sociais. Na ACUDA, todos eram chamados pelo nome e o crachá era de uso obrigatório. Os presos tinham uma rotina de atividades organizada e a possibilidade de estudar e/ou exercer um ofício. A renda obtida pelas açôes era utilizada para a manutenção da Associação e o que restava era dividido entre os presos igualitariamente. Esta, muitas vezes, era a única renda que alguns deles possuíam, a qual enviavam a suas famílias e ainda era usada para comprar materiais de higiene ou outra necessidade. Além da renda, uma importante questão era o sentimento de pertença e de participação nas decisôes sobre as atividades desenvolvidas.

Osler e Starkey (2006) atentam para o fato de que a cidadania possibilita o exercício dos direitos e garantias a que o Estado é responsável. Para uma efetiva prática da cidadania, Lister (1998) afirma ser necessário que haja a prática, mas a capacidade de ação só é dada pela titularidade de direitos, ou seja, cidadão é aquele que pode desfrutar dos direitos necessários para a ação e para a participação social e política. A cidadania, então, relaciona-se com o sentimento de pertencimento a uma comunidade ou grupo.

Para Oesler e Starkey (2006), a cidadania tem ligação direta com direitos humanos, à vida e à saúde. Os presos estão sob tutela do Estado e sua cidadania é parcialmente exercida, visto que alguns de seus direitos são retirados ao terem sua liberdade restringida. Apesar de assegurados, constitucionalmente, muitos dos direitos que os tornam cidadãos, grande parte dos presos brasileiros não os acessa (SANTANA, 2014). Isso acontece porque a visão do Estado e da sociedade é a de que o preso é um ser demonizado, sem alma e sem sentimentos, não tendo condiçóes de aprender e, consequentemente, sem direito a acessar o conhecimento e a ferramentas capazes de possibilitar uma mudança em suas vidas (CARVALHO, 2009). Sobre isso, tive a oportunidade de vê-los e acompanhá-los no trabalho manuseando ferramentas e em nenhum momento senti medo, não vi nenhuma demonstração de agressividade. Eram homens que sentiam tanto quanto as pessoas que não estavam na condição de aprisionamento. Porém, alguns, por estarem há bastante tempo inseridos em contextos de violência, mostravam-se mais insensíveis, o que ia sendo trabalhado com as PICS.

A prática da cidadania permite que o indivíduo aja individualmente ou em conjunto, produzindo mudanças ou influenciando decisóes. O exercício da cidadania 
vai muito além do direito ao voto, incluindo a participação nas decisões que afetam suas vidas (OSLER e STARKEY, 2006). Nessa direção, presos associados podiam participar das assembleias, onde todas as decisôes referentes às atividades realizadas na ACUDA eram tomadas em conjunto. Cabe ressaltar que nem todos os presos participavam deste processo: somente aqueles que ganhavam a confiança da equipe diretiva, que era responsável por permitir que os presos se associassem.

Além de fornecer uma alternativa de trabalho, as PICS podiam ser também uma ferramenta para que os presos fossem mais autônomos e conscientes das suas açôes e do que podiam (ou não) fazerem ao participarem da sociedade, funcionando como potência de vida. A saúde aqui está vinculada à descoberta destas novas possibilidades de existência, incluindo o pertencimento a um grupo, ser dotado de valor político, reivindicar seus direitos e ter uma profissão ou ofício capaz de auxiliar na sua sobrevivência. Para Bernardes, Pelliccioli e Guareschi (2010), ao tratar somente o biológico, as ações em saúde têm a finalidade de fazer o indivíduo viver ou deixá-lo morrer, diferentemente de quando se considera a multiplicidade de formas de vida, quando as açôes são para transformar o indivíduo-população em cidadão.

Por fim, ressaltamos que a cidadania promovida pelas PICS ainda estava restrita aos muros da ACUDA e focada na modificação do indivíduo, o que não garante que ela será efetivada "fora dos muros". Assim que deixarem a prisão, os presos enfrentarão o estigma de serem ex-presidiários e, neste sentido, caberia questionar como é possível que a sociedade venha a considerar essas pessoas como cidadãos.

\section{Consideraçóes Finais}

A partir de uma experiência etnográfica, o estudo procurou articular teoricamente a noção de potência de vida às PICS ofertadas aos presos que frequentam a ACUDA. Mesmo sob condiçóes tão adversas, de onde emerge a potência de vida, as PICS utilizadas pela Associação mostraram-se como uma possibilidade de saúde e (re) existência aos presos. Nessa situação, as PICS foram entendidas enquanto práticas que, promoviam o afeto, o cuidado, a liberdade e a cidadania, ainda que restritos aos muros da Associação, mas fornecendo ferramentas para que os presos se instrumentalizassem pessoalmente e para retornar ao convívio social.

Enquanto Práticas de Afeto, as PICS promoviam a possibilidade destes corpos pensarem e agirem diferentemente do que estavam acostumados. Como descrito nas 
trajetórias de Marte e Netuno, ao serem afetados, estes indivíduos estavam em um processo de ressignificação de suas trajetórias, ensaiando novos modos de existir. Ainda demonstraram ser Práticas de Cuidado, sendo, muitas vezes, o único cuidado a que muitos presos tinham acesso. As PICS, tal como ofertadas na instituição, favoreciam uma visão integral de ser humano, promovendo modificaçóes na forma de ser e estar no mundo.

Entendemos também as PICS como Práticas de Liberdade, visto que auxiliavam os presos na negociação entre o que eram e o que podiam ser, entre o que queriam e o que podiam fazer, exercendo a liberdade mesmo que circunscrita. Este exercício mostrou-se vinculado às PICS enquanto Práticas de Cidadania, já que ter uma rotina, exercer um ofício, estudar e tornar-se terapeuta, possibilitava oportunidades de inserção social, mesmo que representassem, no momento, um vir-à-ser. Por si só, isso não garantia o não retorno ao crime, mas demonstrou ser uma alternativa possível e que, em articulação mais ampla com outros espaços sociais, representaria uma estratégia sustentável.

Destacamos que as práticas apresentadas se constituíam em práticas de intervenção focadas no indivíduo, sendo necessário que outras instâncias, extraindivíduo e extra-ACUDA, fossem acionadas e modificadas. Seria preciso, portanto, que houvesse articulação entre a ACUDA e os outros setores/atores envolvidos para as modificaçôes que vinham sendo produzidas intramuros tivessem eco fora deles, podendo atingir e incitar mudanças na própria PNAISP, por exemplo.

Seria, ainda, interessante integrar as atividades ofertadas pela Associação com os serviços de saúde nas prisôes, nas quais poderiam atuar presos que receberam formação terapêutica. Estas açôes poderiam integrar as três Políticas de Saúde que atuam neste contexto: a PNAISP, a PNAB e, dentro dela, a Política Nacional de Práticas Integrativas e Complementares em Saúde. Novos estudos poderiam enfocar tais aspectos, atentando para o fato de que a aplicação das PICS deve fortalecer os processos de cuidados primários nas prisôes, garantindo os direitos humanos fundamentais a essas pessoas.

\section{Agradecimento}

O presente trabalho foi realizado com apoio da Coordenação de Aperfeiçoamento de Pessoal de Nível Superior - Brasil (CAPES) - Código de Financiamento 001. 


\section{Referências}

ASSIS, A. M.; FRIEDE, R. R. Questóes de cidadania: o trabalho como direito social no cárcere e fora dele. Revista Legis Augustus, Rio de Janeiro, v.5, p. 22-30, 2014.

ADORNO, S. A prisão sob a ótica de seus protagonistas. Itinerário de uma Pesquisa. Tempo Social, São Paulo, v. 3, p. 7-40, 1991. Disponível em: http://www.scielo.br/scielo.php?script=sci_ arttext\&pid=S0103-20701991000100007. Acesso em 22 de julho de 2019.

AGAMBEN, G. Homo Sacer: o poder soberano e a vida nua. Belo Horizonte: Editora UFMG, 2007.

ANGROSINO, M. Etnografia e observação participante. Porto Alegre: Artmed: 2009.

ARÁN, M.; PEIXOTO JÚNIOR, C. A. Vulnerabilidade e vida nua: bioética e biopolítica na atualidade. Revista de Saúde Pública, v. 41, p. 849-57, 2007.

ARENDT, H. A condição humana. Rio de Janeiro: Forense, 1989.

BARCELLOS, A.P. Violência urbana, condiçóes das prisões e dignidade humana. Revista de Direito Administrativo, Rio de Janeiro, v. 254, p. 39-65, mai. 2010.

BRASIL, Portaria Interministerial No 1, de 2 de janeiro de 2014.

BERNARDES, A. G., PELLICCIOLI, E. C., GUARESCHI, N. M. Trabalho e produção de saúde: práticas de liberdade e formas de governamentalidade. Psicologia \& Sociedade; p. 5-13, 2010. Disponível em: http://www.scielo.br/scielo.php?pid=S0102-71822010000100002\&script=sci_ abstract\&tlng=pt. Acesso em 22 de julho de 2019.

CAPRARA, A.; LANDIM, L. P. Etnografia: uso, potencialidades e limites na pesquisa em saúde. Interface, Botucatu, v. 12, p. 363-376, 2008.

CASTRO, E. Vocabulário de Foucault: um percurso pelos seus temas, conceitos e autores. Belo Horizonte: Autêntica, 2009.

DELEUZE, G. A ilha deserta: e outros textos. São Paulo: Iluminuras, 2006.

DELEUZE, G. Espinosa - Filosofia Prática. São Paulo: Escuta, 2002.

ESPINOSA, B. Ética. 2a Ed. Belo Horizonte: Autêntica, 2008.

GARCEZ, P. M.; BULLA, G. S.; LODER, L. L. Práticas de pesquisa microetnográfica: geração, segmentação e transcrição de dados audiovisuais como procedimentos analíticos plenos. Rev. Delta, p. 257-288, 2014.

GEERTZ, C. A interpretação das culturas. Rio de Janeiro: Livros Técnicos e Científicos, 1989.

GOMES, L. G.; SILVA JÚNIOR, N. Experimentação política da amizade a partir da teoria dos afetos de Espinosa. Cadernos Espinosanos/Estudos Sobre o século XVII. São Paulo: Departamento de Filosofia da USP, p. 39-59, 2013. 
HARDT, M. O trabalho afetivo. In.: PELBART, P.P.; COSTA, R. (Orgs.), Cadernos de subjetividade: o reencantamento do concreto. São Paulo: Hucitec, p. 143-157, 2003.

JESUS, L. O.; SCARPARO, H. B.; LERMEN, H. S. Desafios profissionais no campo da saúde no sistema prisional: dilemas na interface entre a saúde e a segurança. Aletheia, Canoas, n. 41, p. 39-52, 2013.

FOUCAULT, M. Vigiar e punir: nascimento da prisão. Petrópolis: Vozes, 1995.

FOUCAUlT, M. Em defesa da sociedade: Curso dado no Collège de France (1975-1976). São Paulo: Martins Fontes, 1999.

FOUCAULT, M. Ética, sexualidade e politica: Ditos e escritos $V$. Rio de Janeiro: Forense Universitária, 2006.

LISTER, R. Citizen in action: citizenship and community development in a Northern Ireland context. Community Development Journal; p. 226-235, 1998. Disponívelem: https://www.jstor. org/stable/44257416?seq=1\#page_scan_tab_contents. Acesso em 15 de março de 2018.

LUZ, M. T. Novos saberes e praticas em Saúde Coletiva. Estudos sobre Racionalidades Medicas e Atividades Corporais. São Paulo: Hucitec, 2004.

LUZ, M. T. Fragilidade social e busca de cuidado na sociedade civil de hoje. In: Pinheiro R., Mattos R.A. Cuidado: as fronteiras da integralidade. Rio de Janeiro: IMS/UERJ, CEPESC, ABRASCO; 2005. p. 9-20.

MACHADO, L. D.; LAVRADOR, M. C. C. Por uma clínica da expansão da vida. Interface, Botucatu, v.13, p.515-21, 2009.

MALLMANN, C. L.; ROCHA, C. M. F. Práticas (não) hegemônicas em saúde: uma análise a partir dos Estudos Culturais. Semina: Ciências Sociais e Humanas, Londrina, v. 38, p. 51-62, 2017.

MIZOGUCHI, H. D. Os dispositivos e o cuidado de si: a invenção do presente. Estudos de Psicologia, v. 21, p. 69-79, 2016.

MINAYO, M. C. S.; CONSTANTINO, P. Deserdados sociais: condiçóes de vida e saúde dos presos do estado do Rio de Janeiro. Rio de Janeiro: Fiocruz, 2015.

NEGRI, A. Exílio: Seguido de Valor e Afeto. São Paulo: Ilu-minuras, 2001.

OMS. Estrategia de la OMS sobre medicina tradicional 2014-2023. China, Organización Mundial de La Salud, 2014.

ORTEGA, F. Amizade e estética da existência em Foucault. Rio de Janeiro: Graal, 1999.

OSLER, A.; STARKEY, H. Education for democratic citizenship: a review of research, policy and practice 1995-2005. Research Papers in Education, v. 21, n. 4, p. 433-466, 2006. 
PINHEIRO, R.; MACHADO, F. R.; GUIZARDI, F. L. Cidadania no cuidado: um ensaio sobre os caminhos de se (re)pensar a integralidade nas Práticas Integrativas e Complementares em Saúde. In.: Barreto, A. F. (org.) Integralidade e saúde: epistemologia, política e práticas de cuidado. Recife: Universitária UFPE, p. 75-97, 2011.

PORTO, R. Crime Organizado e Sistema Prisional. 1. ed. São Paulo: Atlas, 2008.

SAFATLE, V. O circuito dos afetos: Corpos politicos, desamparo e o fim do indivíduo. Belo Horizonte: Autêntica Editora, 2a Edição, 2018.

SANTANA, I. S. A muralha de ferro que anula a cidadania do homem como preso. Tese de Doutorado. Departamento de Direito da Universidade Autônoma de Lisboa, 2014.

TESSER, C. D. Práticas complementares, racionalidades médicas e promoção da saúde: contribuições poucos exploradas. Cadernos de Saúde Pública, Rio de Janeiro, v. 25, n.8, p. 1732-1742, 2009.

ZEPPINI, P. S. Deleuze e o Corpo: articulaçóes conceituais entre Deleuze, Nietzsche e Espinosa em função da problemática do corpo. Dissertação de Mestrado. Departamento de Filosofia e Ciências Humanas da Universidade Estadual de Campinas, Campinas, 2010. 


\section{Abstract}

\section{(Re)existence and power of life: integrative and complementary practices in health for prisoners}

This study aimed to discuss how the Integrative and Complementary Practices in Health (ICPH) have been a possibility of health and existence to inmates who attend the Cultural Association of the Development of the Inmate and Egress (ACUDA) of Porto Velho, RO. An ethnographic research was conducted during four months of participant observations of daily activities promoted by the Association as well as indepth interviews with inmates and staff. ACUDA assisted about ninety prisoners in close custody from three prisons in the city. Their daily routine in ACUDA included, in addition to offering ICPH, labor, educational, leisure and spiritual activities. Based on a poststructuralist analysis of the data and focusing the trajectories of two prisoners, it is discussed how ICPH presented itself as life enhancers. The ICPH enhanced life power from Practices of Affection, Care, Freedom and Citizenship, showing to be an important tool of subjective change, opening other meaning and life possibilities for prisoners. It is argued that, in order to have an effective social reintegration of prisoners, practices aimed to individual transformation need to be combined with broad social changes that recognize the citizenship and rights of these people.

> Keywords: Complementary Therapies; Prisons; Power of life; Self Care. 